\title{
Long-Term Outcome of Dentatotomy in a Dystonic Patient
}

\section{Avaliação a longo prazo de paciente distônico submetido a dentatotomia}

\author{
Manoel Jacobsen Teixeira1,2 Carina C. França ${ }^{3}$ Daniel Ciampi de Andrade ${ }^{1,4}$ \\ Luis Augusto Carvalho Rogano ${ }^{2}$ Guilherme Lepski ${ }^{2}$ Erich Talamoni Fonoff ${ }^{2}$ Rubens Gisbert Cury ${ }^{3}$
}

${ }^{1}$ Pain Center, Department of Neurology, Faculdade de Medicina, Universidade de São Paulo, SP, Brazil

2 Neurosurgery Division, Department of Neurology, School of

Medicine, Universidade de São Paulo, SP, Brazil

${ }^{3}$ Movement Disorders Center, Department of Neurology, Faculade de

Medicina, Universidade de São Paulo, SP, Brazil

4 Pain Center, Instituto do Câncer do Estado de São Paulo, SP, Brazil

\author{
Address for correspondence Rubens Gisbert Cury, MD, PhD, \\ Neurosurgery Division, Department of Neurology, Faculdade de \\ Medicina da Universidade de São Paulo, Avenida Doutor Arnaldo, 455 - \\ Cerqueira César, São Paulo - SP, 01246-904, Brazil \\ (e-mail: rubens.cury@hc.fm.usp.br).
}

Arq Bras Neurocir 2016;35:307-309.

\begin{abstract}
Dystonia is characterized by sustained or intermittent muscle contractions leading to abnormal movements and impairment in daily activities. Stereotactic dentatotomy has

Keywords

- dystonia

- dentatotomy

- cerebral palsy

\section{Resumo}

Palavras-chave

- distonia

- dentatotomia

- paralisia cerebral been a treatment option in cases of spasticity or dystonia, especially in patients with cerebral palsy, but the long-term effect of dentatotomy in dystonia is still unknown. Here we describe a dystonic patient who underwent dentatotomy for symptomatic treatment of refractory dystonia and whose 20-year follow-up showed improvement in symptoms.

A distonia é caracterizada por contrações musculares intermitentes ou sustentadas que levam a movimentos anormais e ao comprometimento das atividades cotidianas. A dentatotomia estereotáxica tem sido uma opção de tratamento nos casos de espasticidade ou distonia, especialmente em pacientes com paralisia cerebral, mas o efeito a longo prazo da dentatotomia na distonia ainda é desconhecido. Descrevemos aqui um paciente submetido a dentatotomia para tratamento sintomático de distonia refratária e cujo acompanhamento por 20 anos demonstrou melhora nos sintomas.
\end{abstract}

\section{Introduction}

Dystonia is a neurologic disorder characterized by sustained or intermittent muscle contractions causing abnormal movements and/or postures ${ }^{1}$ and involves a heterogeneous group of disorders with many underlying causes, both known and unknown. Etiologic classification relates to whether dystonia is inherited, acquired, or due to identifiable brain

received

May 17, 2016

accepted

September 22, 2016

published online

October 25, 2016
DOI http://dx.doi.org/ 10.1055/s-0036-1593836. ISSN 0103-5355. abnormalities. ${ }^{1}$ Dystonia can arise secondary to brain damage, including stroke, trauma, or adverse medication effect (tardive dystonia), or as a symptom of other diseases, such as Parkinson disease. Pharmacologic therapies, especially the anticholinergic agents, can provide modest symptomatic improvement but can lead to significant adverse effects. Botulinum toxin injections can provide relief in many patients. ${ }^{1,2}$ However, the injections must be repeated every few
Copyright $\odot 2016$ by Thieme-Revinter

Publicações Ltda, Rio de Janeiro, Brazil
License terms

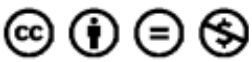


months, patients can become resistant, and adverse effects, such as weakness, are not uncommon. Surgical interventions have included rhizotomy, for cervical dystonia; ablation of the thalamus (thalamotomy); internal globus pallidus (pallidotomy); dentate nucleus (dentatotomy), and deep brain stimulation for more generalized dystonias. ${ }^{1-3}$

For many decades, stereotactic dentatotomy has been a treatment option in cases of spasticity ${ }^{4}$ or dystonia, especially in patients with cerebral palsy. Though vastly used in the past, in the last twenty years, published papers on the matter were rare. In this line, the longterm effect of dentatotomy in dystonia is still unknown. Here we describe a dystonic patient who underwent dentatotomy for symptomatic management and was monitored for 20 years.

\section{Case Report}

A 39-year-old right-handed man presented with dystonia since early childhood due to hypoxia during birth. His symptoms were mainly distal on four limbs, as well as on larynx, and significantly impaired his work, study and leisure activities. He had no cognitive disability, no motor involvement other than dystonia/dystonic tremor, and no remarkable neuroimaging findings. All the treatment attempts were frustrated, including physical therapy and medical therapy with diazepam, clonazepam, valproic acid and trihexyphenidyl. By the time the patient was 20 years-old, in 1995, due to refractory symptoms and with patient's consent, a left dentatotomy was performed. The stereotactic coordinates of the targets were determined based on previously published anatomical studies. ${ }^{5,6}$ The target point was located $10-$ $12 \mathrm{~mm}$ behind the fastigial point, $3-5 \mathrm{~mm}$ below the fastigial line, and $8-10 \mathrm{~mm}$ from the midline. The patient reported good outcome in the motor function, improvement in left side dystonia, action tremor, walking and performing manual tests, such as drinking. Despite the improvement in dystonia, our patient remained symptomatic on the right side, and in the same year, deep brain stimulation (DBS) was placed on the left subthalamic nucleus. Deep brain stimulation was set as bipolar (contact 0 as anode and 2 as cathode), at $2,1 \mathrm{~V}, 270 \mu \mathrm{s}$ and $125 \mathrm{~Hz}$. Twenty years after the first surgery (dentatotomy), the Unified Dystonia Rating Scale (UDRS) was 9,5 (highest score on this scale: 44), with symptoms predominantly in the distal parts of the upper limbs and larynx. He was otherwise asymptomatic.

The patient had the impression that the procedures improved $\sim 50 \%$ of his dystonia, mainly on his legs, now considered asymptomatic.

\section{Discussion}

Dentate lesions result in prolonged reaction time associated with a corresponding increase in the latency of movement and related responses of cortical neurons, and may affect movement programming through the cortico-neocerebellum cortical loop. ${ }^{7}$ It may improve abnormal movements through decreasing in the facilitatory outflow of the dentate nucleus over the motor cortex. ${ }^{8}$ Basal ganglia or cerebral cortex damage tend to lead the contralateral cortex to hyperexcitability that can be reduced with dentatotomy. ${ }^{9,10}$

In agreement with this hypothesis, Schneider and Crosby ${ }^{9}$ found that the cerebellar cortex aided abnormal posturing and hypertonia in patients with cerebral palsy.

After those results, several studies showed benefits of dentatotomy in dystonia, choreoathetosis and spasticity in cerebral palsy patients. ${ }^{11-14}$ Improvement seemed more substantial in the lower limbs, ${ }^{15}$ which happened in our patient. A combination of dentatotomy and thalamo-subthalamotomies showed even better result in cases of spasticity than dentatotomy alone. ${ }^{16}$ To our knowledge, the case reported is the first to show the association between dentatotomy and subthalamic deep brain stimulation.

Despite the report of good outcomes seen in the literature, the benefit over long periods is unknown. In 1970, Heimburger ${ }^{17}$ reported improvement in 50 out of 61 patients submitted to dentatotomy, with benefits lasting from 4 months to 5 years and relapse in 11 cases. Siegfried and Verdie ${ }^{18}$ described a reduction in improvement after months or years of the operation, with a failure rate of $10 \%$ in 6 months, $20 \%$ in 2 years and $24 \%$ in 3 years of follow-up. Our patient remained stable after 20 years follow-up.

Finally, although dentatotomy can be a safe treatment of spasticity and dystonia, the current trend is the DBS surgery, which usually brings better results with fewer side effects. ${ }^{19}$ Even so, ablative surgery appears to be a good option for a proportion of patients to whom the DBS is contraindicated, as well as for those with social problems, ${ }^{20}$.

\section{Conclusion}

This case report showed sustained benefit of dentatotomy associated with unilateral subthalamic DBS for secondary dystonia. The dentatotomy can be considered as a good option for refractory dystonia, which should be further explored in future studies. Our study protocol was safe; it laid the groundwork for larger studies regarding dentatotomy, with or without DBS, in this patient population.

\section{References}

1 Balint B, Bhatia KP. Dystonia: an update on phenomenology, classification, pathogenesis and treatment. Curr Opin Neurol 2014;27(4):468-476

2 Fox MD, Alterman RL. Brain Stimulation for Torsion Dystonia. JAMA Neurol 2015;72(6):713-719

3 Mueller J, Skogseid IM, Benecke R, et al; Deep-Brain Stimulation for Dystonia Study Group. Pallidal deep brain stimulation improves quality of life in segmental and generalized dystonia: results from a prospective, randomized sham-controlled trial. Mov Disord 2008;23(1):131-134

4 Teixeira MJ, Schroeder HK, Lepski G. Evaluating cerebellar dentatotomy for the treatment of spasticity with or without dystonia. Br J Neurosurg 2015;29(6):772-777

5 Heimburger RF, Whitlock CC. Stereotaxic destruction of the human dentate nucleus. Confin Neurol 1965;26(3):346-358

6 Slaughter DG, Nashold BS Jr. Stereotactic coordinates for the human dentate nucleus. Confin Neurol 1968;30(5):375-384 
7 Spidalieri G, Busby L, Lamarre Y. Fast ballistic arm movements triggered by visual, auditory, and somesthetic stimuli in the monkey. II. Effects of unilateral dentate lesion on discharge of precentral cortical neurons and reaction time. J Neurophysiol 1983;50(6):1359-1379

8 Sukoff MH, Ragatz RE. Cerebellar stimulation for chronic extensor-flexor rigidity and opisthotonus secondary to hypoxia. Report of two cases. J Neurosurg 1980;53(3):391-396

9 Schneider RC, Crosby EC. THE INTERPLAY BETWEEN CEREBRAL HEMISPHERES AND CEREBELLUM IN RELATION TO TONUS AND MOVEMENTS. J Neurosurg 1963;20:188-198

10 Grimm RJ, Rushmer DS. The activity of dentate neurons during an arm movement sequence. Brain Res 1974;71(2-3):309-326

11 D'Andrea F, Ferrari E, De Divitiis E, Mattioli G. [Immediate and late effects of monolateral and bilateral stereotaxic coagulation of the dentate nucleus on "dyssynergia cerebellaris myoclonica"]. Minerva Neurochir 1966;10(4):375-379

12 Krayenbühl H, Siegfried J. [Stereotaxic surgery of the dentate nucleus in treatment of hyperkinesia and spastic conditions]. Neurochirurgie 1969;15(1):51-58
13 Nashold BS Jr, Slaughter DG. Effects of stimulating or destroying the deep cerebellar regions in man. J Neurosurg 1969;31(2): $172-186$

14 Zervas NT. Long-term review of dentatectomy in dystonia musculorum deformans and cerebral palsy. Acta Neurochir (Wien) 1977(Suppl 24):49-51

15 Hitchcock E. Dentate lesions for involuntary movement. Proc R Soc Med 1973;66(9):877-879

16 Mundinger F, Ostertag C. Multilocular lesions in the therapy of cerebral palsy. Acta Neurochir (Wien) 1977(Suppl 24):11-14

17 Heimburger $F$. The role of the cerebellar nuclei in spasticity. Confin Neurol 1970;32(2):105-113

18 Siegfried J, Verdie JC. Long-term assessment of stereotactic dentatotomy for spasticity and other disorders. Acta Neurochir (Wien) 1977(Suppl 24):41-48

19 Teixeira MJ, Cury RG, Galhardoni R, et al. Deep brain stimulation of the dentate nucleus improves cerebellar ataxia after cerebellar stroke. Neurology 2015;85(23):2075-2076

20 Lang AE, Houeto J-L, Krack P, et al. Deep brain stimulation: preoperative issues. Mov Disord 2006;21(Suppl 14):S171-S196 